\title{
A Non-Random Walk Down Hollywood Boulevard: Celebrity Deaths and Investor Sentiment
}

\author{
Gabriele M. Lepori ${ }^{\text {a }}$
}

This version: August 19, 2020

\begin{abstract}
Motivated by psychological evidence that the public experiences emotional distress in response to the deaths of popular figures, I employ the deaths of 1,391 Hollywood Walk of Fame celebrities as natural experiments to identify a series of exogenous public mood changes over the period 1926-2009. Consistent with the psychological theories maintaining that sadness encourages individuals to favor high-risk/high-reward investments, I find that U.S. stock returns are abnormally high immediately after the death of a major celebrity. This effect is particularly large during periods of high market-level uncertainty $(+0.40 \%)$ and for stocks headquartered in the city where the celebrity died $(+0.26 \%)$.
\end{abstract}

JEL Classification Codes: G02, G11, G12, G14

Keywords: Investor sentiment, celebrity deaths, risk taking, local trading bias.

\footnotetext{
a Current affiliation: Department of Banking and Finance, Southampton Business School, University of Southampton, Highfield Campus, Southampton SO17 1BJ, United Kingdom. Phone: +44 (0)23 8059 4219. Email: g.m.lepori@ soton.ac.uk. This study began when I was at Copenhagen Business School, Denmark. I wish to thank my research assistant, Qiushi Zhang, who helped collect the data. This paper has benefited from comments from Richard Warr (Editor), an anonymous reviewer, and participants at the Meeting of the Academy of Behavioral Finance and Economics in New York, the Meeting of the Financial Management Association in Atlanta, the conference on East Asia finance in Taipei, the Meeting of the Eastern Finance Association in St. Pete Beach, and the Meeting of the Financial Management Association in Venice. All remaining errors are mine. The study was approved by the Faculty Ethics Committee of the University of Southampton (ERGO number: 55370). Sources of financial support for this particular research: none. Potential conflicts of interest to disclose: none.
} 


\title{
A Non-Random Walk Down Hollywood Boulevard: Celebrity Deaths and Investor Sentiment
}

\begin{abstract}
Motivated by psychological evidence that the public experiences emotional distress in response to the deaths of popular figures, I employ the deaths of 1,391 Hollywood Walk of Fame celebrities as natural experiments to identify a series of exogenous public mood changes over the period 1926-2009. Consistent with the psychological theories maintaining that sadness encourages individuals to favor high-risk/high-reward investments, I find that U.S. stock returns are abnormally high immediately after the death of a major celebrity. This effect is particularly large during periods of high market-level uncertainty $(+0.40 \%)$ and for stocks headquartered in the city where the celebrity died $(+0.26 \%)$.
\end{abstract}




\section{Introduction}

In modern society, the lives and tribulations of so-called celebrities attract the interest of millions of people. Psychologists have long documented that fans exhibit an obsessive fascination with their favorite actors, singers, and the like; this fascination is so strong that fans tend to identify themselves and develop imaginary relationships with them (Levy, 1979). Though all the interaction is one-way, such relationships are experienced as real, and audiences tend to look to media personalities as "real friends" (Hall and Reid, 2009). It follows from this that ordinary people often feel emotionally involved with celebrities. For example, when singer Michael Jackson died in 2009, a massive public outpouring of grief immediately took place in the U.S. and across the globe (Sanderson and Cheong, 2010). History shows that such emotional reactions are far from uncommon in response to the deaths of popular and beloved celebrities; Rudolph Valentino, Elvis Presley, John Lennon, Princess Diana, and Steve Irwin (aka "the crocodile hunter") are just a few major examples of celebrities whose deaths sent emotional shock waves through the Western world.

Human tragedy aside, these events represent natural experiments that can help economists to investigate in the field how incidental mood changes affect people's decisions involving risk. ${ }^{1}$ Incidental mood is mood "that is unrelated to the decision at hand" and may originate from disparate sources (Loewenstein and Lerner, 2003). After reviewing the past 35 years of work on the relationship between mood and decision making, Lerner et al. (2015) concluded that "incidental emotions often produce influences that are unwanted and nonconscious" and "many psychological scientists now assume that emotions are, for better or worse, the dominant driver of most meaningful decisions in life". Andrade (2005) summarized the two main streams of research on the impact of mood on risk taking: according to the dynamic affect regulation theories, negative mood encourages people to choose

\footnotetext{
${ }^{1}$ Mood can be considered as a special case of market sentiment (see Baker and Wurgler, 2006). In this paper, as it is common in the behavioral finance literature, I use the terms sentiment, mood, affect, and emotions interchangeably.
} 
high-risk/high-reward options to repair their moods; according to the static affect evaluation theories, instead, negative mood "bias[es] evaluative judgment and actions in a congruent manner", promoting more pessimistic views and inducing individuals to shy away from risk.

In this study, I employed celebrity deaths as a source of exogenous changes in the mood of the US public, which allowed me to estimate the impact of incidental mood changes on the demand for risky assets. My empirical strategy was motivated by three basic facts: (i) media communication scholars and psychologists have documented that the emotional attachment that ordinary people develop toward celebrities can be so strong that the deaths of major celebrities may send negative emotional waves through large portions of the population; (ii) celebrity culture is pervasive in the U.S. (e.g., Kurzman et al., 2007), and historical daily data about the dynamics of the U.S. stock market are readily available going back to the 1920 s, which is precisely when the celebrity phenomenon began to flourish (Leff, 1997); (iii) "[t]he U.S. equity market is characterized by widespread direct stock ownership by retail investors", who "spend far less time on investment analysis" than institutional investors (Kumar and Lee, 2006); moreover, the former's decisions and expectations are more sensitive to fluctuations in sentiment than the latter's (Kostopoulos and Meyer, 2020). Therefore, it is plausible to hypothesize that the deaths of popular celebrities affect the net demand for risky assets through their influence on unsophisticated investors' moods and risk-taking propensities.

For the empirical analysis I relied on a sample of 1,391 deaths (from 1926 to 2009) of public figures who were inducted into the Hollywood Walk of Fame (HWF) and consequently were unambiguously recognized as celebrities by the U.S. public. Controlling for economic news, seasonalities, and behavioral factors, I estimate that the death of a major celebrity is immediately followed by an abnormal $0.16 \%$ increase in stock returns. As the discussion in section 7 will make clear, the size of this effect is practically relevant when compared with (1) the average size of the effects reported in sentiment studies published in leading finance journals, (2) typical trading costs for 
institutional investors, and (3) the effects of scheduled macroeconomic announcements to which the public usually pays close attention.

This finding is consistent with the dynamic affect regulation theories, according to which the negative public mood spurred by the death of a major celebrity is expected to promote risk-prone behavior and increase the net demand for risky assets. Consistent with the view that increased risktaking is the mechanism behind the observed phenomenon, I found that lottery sales increase after major celebrity deaths. Furthermore, consistent with the interpretation that the celebrity-death effect is driven by investor mood changes, I found that (i) the size of the market reaction to a celebrity death is increasing in the popularity of the deceased celebrity; (ii) the market reaction is weaker in response to a death that is, to some extent, expected and gives the public more time to prepare psychologically; (iii) the market reaction is stronger and economically large $(+0.40 \%)$ when market-level uncertainty is higher, and consequently unsophisticated investors can equally plausibly defend a wide range of stock valuations; (iv) consistent with the investor sentiment literature (e.g., Baker and Wurgler, 2006), the celebrity-death effect is stronger in portfolios of stocks that are more difficult to value and harder to arbitrage; (v) the celebrity-death effect is weakest in the largest-cap segment, which is dominated by institutional investors, and strongest in the high-book-to-market ratio segment, which is one of the "natural habitats" of retail investors (Kumar and Lee, 2006); (vi) lastly, consistent with the local trading bias literature, according to which investors overly own and trade the stocks of local firms in their neighborhood (e.g., Zhu, 2002), celebrity deaths have a larger and economically meaningful impact $(+0.26 \%)$ on the returns of firms headquartered in the cities where such deaths occur.

The rest of the paper is organized as follows. Section 2 discusses the celebrity phenomenon and the evidence on the public's emotional reaction to celebrity deaths. Section 3 reviews the literature on the influence that negative mood exerts on decision-making under risk, section 4 presents the 
hypotheses under scrutiny, and section 5 describes the celebrity data and the controls. Section 6 details the econometric analysis, and section 7 discusses the relevance of the results. Section 8 concludes.

\section{The mechanics of celebrity}

\subsection{Fame and psychological attachment to celebrities}

Celebrity can be considered a novel social status that emerged at the beginning of the $20^{\text {th }}$ century on the coasts of North America and then spread to the rest of the world (Kurzman et al., 2007). According to Leff (1997), "the mass media of the late 1920s transformed the relationship between Americans and their public figures. Capitalizing on professional sports, network radio, and Hollywood motion pictures, the press [...] produced a desire to know the renowned - who they were how they lived and what they thought". Today, celebrities occupy a prominent space in the daily lives of most Americans (Gamson, 1994), and numerous scholars have observed that contemporary American culture exhibits an obsessive fascination with celebrities. What makes celebrities so special is their acquired ability to attract people's attention and, somehow, "matter to the rest of us" (Kurzman et al., 2007). Horton and Wohl (1956) suggested that, through repeated exposure to media personalities, viewers/readers develop "a sense of intimacy", or friendship, with them; according to this interpretation, celebrities become what has been defined as "intimate strangers". Given that TV consumption is so pervasive in the U.S., it is not surprising that Caughey (1984) claimed that, in the daily lives of many Americans, "media consumption directly parallels actual social interaction" to the point that "the social world of Americans includes more media figures than actual persons".

\subsection{The public's reaction to celebrity deaths}

Attachment and loss are natural parts of life. "Grief following loss through death is considered a universal, normal human reaction", and the emotional response experienced by the bereaved is believed 
to peak immediately after the loss and to decline over time (Malkinson, 2001). Sadness is the dominant and most common feeling experienced in the normal grieving process (Bowlby, 1998). While the emergence of negative affective states in the bereaved appears as natural in response to the loss of a family member, friend, or acquaintance, it is perhaps more surprising that, as several scholars have argued, the deaths of popular and beloved celebrities may spark similar feelings of grief in the general public (Turner, 2004; Gibson, 2007a; 2007b; Stever, 2010). Some anecdotal evidence in support of this view is readily available. For example, communication researchers have observed that, immediately following his death in 1980, John Lennon became "an object of mourning", and his murder caused "a profound sense of loss [that] haunted our general culture" (Elliott, 1998). Following Princess Diana's death in 1997, "in homes, coffee shops, bars, hospitals, restaurants, offices, and wherever television reached them, people mourned the loss of an international celebrity like they mourned the loss of a family member or friend" (Brown et al., 2003). The accidental death of Steve Irwin in 2006 caused a "huge outpouring of public grief in Australia and overseas", and his funeral was watched by an estimated TV audience of 300 million people (Gibson, 2007b). Such phenomena are nothing new, as in the 1920s, at the dawn of celebrity culture, an estimated 100,000 people lined the streets of New York to pay tribute to Rudolph Valentino's body following his death (Rambova, 2009).

Scholars have offered various explanations to rationalize why celebrity deaths cause feelings of sadness in the public (Gibson, 2007a; Stever 2010). Regardless of the underlying reason, the existing empirical evidence in this area supports the hypothesis that celebrity deaths generate intense emotional reactions in the population. For instance, when a popular celebrity dies, his or her entry in Wikipedia (a free online encyclopedia) typically sees a very large, abnormal increase in pageviews (Goldenberg, 2018). The medical literature has documented that celebrity deaths, especially by suicide, tend to be followed by increases in population suicide rates (Cheng et al., 2007). The economic literature, instead, 
has shown that, in the market for celebrity memorabilia, demand and prices tend to rise right after the death of a celebrity (Matheson and Baade, 2004).

\section{Negative mood and risk-taking propensity}

Evidence that incidental mood plays a relevant role in decision making has been accumulating at an accelerating rate for the past three decades (Lerner et al. 2015). A growing body of work has focused on how mood affects risk perception, risk tolerance, and decisions involving risk. As is often the case in science, this field sees several competing theories that propose conflicting predictions concerning the effect of negative mood on people's willingness to take risks. According to what Andrade (2005) called the dynamic affect regulation theories, negative mood is expected to foster risk taking. The underlying assumption is that individuals who are experiencing a negative emotional state will take some actions so as to feel better (Isen, 1984). As stated by the mood repair hypothesis (Morris and Reilly, 1987) and the mood management theory (Zillmann, 1988), individuals continuously monitor their affective states; when they self-detect a negative mood, they try to repair it. Since high rewards can repair one's mood and high expected rewards tend to be associated with high risk, the prediction is that, under these circumstances, individuals prefer risky choices to safe ones.

Consistent with these mechanisms, Mittal and Ross (1998) documented that lab subjects in a negative mood condition are more prone to take risks than those in a positive mood. Raghunathan and Pham (1999), using two experiments involving hypothetical gambles and job-selection decisions, found that individuals in whom an incidental sad state has been induced are more likely to choose highrisk/high-payoff combinations. Similar lab findings have been documented by Chuang and Kung (2005) and Conte et al. (2018), among others. As for studies relying on observational data, Bruyneel et al. (2005) found longitudinal evidence that lottery expenditures increase when people's moods deteriorate. Levy and Galili (2008) analyzed a sample of actual trading records from over 3,000 
individual accounts held at an Israeli bank and found that men, low income, and young individuals are net buyers of stocks on cloudy days, consistent with the hypothesis that their demand for risky assets increases when they experience a (weather-induced) negative mood. Cohen-Charash et al. (2013) constructed an index to track the collective mood of traders based on "the use of emotion words in newspaper reports on trader's affect" and found that deactivated unpleasant trader mood (which embodies sadness, despair, depression, etc) is followed by higher NASDAQ's opening prices, which is consistent with the interpretation that sadness induces traders to increase stock purchases.

The predictions of the dynamic affect regulation theories are at odds with what Andrade (2005) called the static affect evaluation theories. According to the latter, negative mood promotes risk avoidance. The argument here is that people are prone to making judgments that are consistent with their mood: individuals in a good mood tend to see the world through pink glasses, while negative affect tends to bias people's perceptions and thoughts toward a more pessimistic view. In line with this interpretation, Johnson and Tversky (1983) found that lab subjects in a bad mood tend to overestimate the probability of a set of life threatening risks. Analogously, Au et al. (2003), who examined simulated trading decisions in a virtual foreign exchange market, found that subjects experiencing a negative mood behave "conservatively in their trading". Supporting evidence has also been produced using nonexperimental data. For example, Kliger and Levy (2003) extracted risk preferences from option prices and concluded that negative mood (proxied by the weather) induces investors to overestimate the probability of adverse events. In the same spirit, Edmans et al. (2007), among others, found that national teams' losses in major sporting events tend to be followed by negative reactions of the domestic stock market, a phenomenon that they attributed to negative investor mood. 


\section{Hypotheses under investigation}

The main hypothesis that I propose draws upon the celebrity literature, the psychology literature on the effects of incidental mood on decision-making under risk, and the behavioral finance literature on the limits to arbitrage. More specifically, the hypothesis maintains that the deaths of popular and beloved celebrities send emotional waves through the population, which, in turn, affect (unsophisticated) investors' willingness to take risks and their trading decisions. Based on the two lines of research presented in section 3, this hypothesis can be divided into two competing hypotheses concerning the direction of this mood-induced effect. As stated by the dynamic affect regulation theories, negative affect is expected to foster the marginal investor's willingness to take risks; conversely, the static affect evaluation theories predict that incidental negative feelings induce individuals to form more pessimistic expectations, behave more conservatively, and shy away from risk. These insights imply the following:

H1: The death of a major celebrity causes negative sentiment, which promotes riskprone (conservative) behavior, increases (reduces) the net demand for risky assets, and raises (lowers) stock returns.

From the main hypothesis, a set of finer and interconnected hypotheses can be derived that can generate additional evidence in support of (or against) the effect under investigation. The first of these is motivated by the fact that not all celebrities are of equal status; while some celebrity deaths spawn huge outpourings of public grief, others go unnoticed, especially if the celebrity in question has lost the public's favor. This argument suggests the following testable hypothesis:

H2: The greater is the popularity of a celebrity, the stronger is the market's reaction to his or her death.

As some scholars have pointed out, "[p]ublic mourning requires ongoing media attention" (Gibson, 2007b), and only "when people feel connected to a celebrity, they are more likely to pay attention to 
stories about that celebrity" (Brown et al., 2003). As a result, media coverage and the public's attention are likely to reinforce each other (Gibson, 2007a). This implies that, when testing hypothesis $H 2$, the amount of media coverage that the death of a celebrity attracts can plausibly proxy for the degree of popularity that the celebrity enjoyed.

A third aspect worthy of investigation concerns the distinction between expected and unexpected celebrity deaths. Deaths that are to some extent anticipated allow people time to process their thoughts and feelings, prepare psychologically, and cope more effectively (Rando, 1986); conversely, sudden deaths are more likely to cause sudden bursts of emotional distress (Lindemann, 1944). Based on these insights, the third testable hypothesis that I consider is:

\section{H3: Expected celebrity deaths produce weaker market reactions than unexpected ones.}

Previous research has documented that "individual investors exhibit stronger behavioral biases [...] when market-level uncertainty is higher" (Kumar, 2009), conceivably because in times of high uncertainty risky assets are harder to value than in normal times, and unsophisticated investors can credibly defend a wider range of stock valuations. Since limits to arbitrage are more severe in the presence of high valuation uncertainty (Jiang et al., 2005), the implication is that higher market-level uncertainty can lead to more serious mispricing of financial assets. According to this logic, fluctuations in investor sentiment caused by celebrity deaths can be expected to have a stronger impact on stock returns during periods when market-level uncertainty is high. As such, the fourth testable hypothesis is:

H4: The market's reaction to the death of a popular celebrity is stronger when market-level uncertainty is high.

Similar reasoning applies to the cross section of stock returns. Previous literature has found evidence that the pricing of securities that feature a higher valuation uncertainty and are more difficult to arbitrage is more sensitive to investor sentiment (Baker and Wurgler, 2006; Kumar, 
2009). As a result, changes in public mood triggered by celebrity deaths can be expected to have a stronger impact on the returns of portfolios of stocks that are more difficult to value and more difficult to arbitrage, which leads to the fifth testable hypothesis:

H5: The death of a popular celebrity has a stronger impact on the returns of stocks that are harder to value and more difficult to arbitrage.

Lastly, previous research has indicated that both individual and institutional investors are affected by a certain degree of local bias, as they disproportionately own and trade the stocks of firms whose headquarters are located near where they live (Coval and Moskowitz, 1999; Zhu, 2002; Bodnaruk, 2009). These patterns are particularly strong in the case of Nasdaq stocks (Loughran and Schultz, 2004), possibly because Nasdaq firms tend to be younger and smaller, share ownership is less dispersed, and many Nasdaq market makers trading a firm's shares are located near the firm's headquarters (Schultz, 2003). The insights generated by this strand of the literature lead to a sixth testable hypothesis:

H6: The death of a celebrity has a stronger impact on the stock returns of firms headquartered near the place where the celebrity died.

There are several arguments in support of this conjecture: celebrities are likely to develop stronger ties with the community where they live; local residents are likely to treat a celebrity living nearby as "one of their own"; celebrities are likely to feature prominently on local media in the areas where they live, and the death of a celebrity living in the neighborhood is likely to attract even more intense media coverage and public attention at the local level than at the state or national level.

\section{Data}

Fame can be achieved in various fields of human activity. In my analysis I focused on the deaths of performers (actors, musicians, TV and radio personalities) who had been explicitly 
acknowledged as celebrities by the U.S. public. More specifically, the sample consists of individuals who were inducted in the HWF between its inception and the end of December 2009. ${ }^{2}$ This choice was motivated by the belief that, unlike other groups of famous people, acclaimed performers are more likely to enjoy nationwide popularity and less likely to provoke conflicting feelings among the public; as a result, their deaths are likely to have an unambiguous negative impact on the average person's mood. Politicians, too, may achieve fame, but they are often polarizing figures, especially in a twoparty system like the U.S.; they may be loved by some and hated by others. To a lesser extent, the same can be said for sports athletes, as most sports teams have fan bases located roughly in their home regions (Giratikanon et al., 2014), and "highly competitive sport encourages strong identification of fans with teams, which $[\ldots]$ may foster negative sentiments toward outgroups" (Lee, 1985).

The HWF consists of a series of sidewalks on Hollywood Boulevard and Vine Street, in Hollywood (CA), where some stars are embedded at 6-foot intervals to pay homage to individuals who have made relevant contributions to the world of entertainment. Receiving a star on the HWF can be considered as a lifetime achievement and proof of one's huge popularity among the public. ${ }^{3} \mathrm{On}$ December 31, 2009, the number of stars embedded in the HWF was 2,317. Using the sources described in the online Appendix, after excluding fictional characters and groups (e.g. The Beatles), I identified the date and place of death of each of the 1,391 HWF celebrities who passed away between January 2, 1926 and December 31, 2009. ${ }^{4}$ The final sample contains 1,346 event days (i.e., days on which at least one HWF celebrity passed away).

A key aspect that needs consideration is that celebrity deaths are not all alike. The death of a popular and beloved celebrity is likely to trigger both widespread media attention and a relevant

\footnotetext{
${ }^{2}$ The sample period ends in 2009 because the Google News Archive project, from which, as I explain later in this section, I collected the data to estimate the popularity of the celebrities in the sample, was discontinued by Google, Inc. at the beginning of the 2010s (Keller, 2011).

${ }^{3}$ See http://www.walkoffame.com/.

${ }^{4}$ The Appendix is available in the supporting materials section online.
} 
emotional response in the public, whereas a celebrity who no longer holds the public's favor is likely to go nearly unnoticed by the nation when passing away. While the former may affect a large segment of the population and have an effect on market prices, the latter should not be expected to influence the marginal investor's decisions. ${ }^{5}$ To construct a proxy for the popularity of each celebrity in the sample and the intensity of the public's emotional reaction to his or her death, I searched Google News Archive and counted the combined number of articles containing the name of such a celebrity that were published in the seven days following his or her death in three major national newspapers: The New York Times, The Los Angeles Times, and The Chicago Tribune (see the online Appendix for the exact methodology). I then constructed two dummy variables to sort the celebrity deaths into two approximately equal-size groups: MajorCeleb (MinorCeleb) takes value 1 on days $t$ and $t+1$, provided the market is open, if a celebrity dies on day $t$ and the number of newspaper articles mentioning his or her name is greater than (less than or equal to) the sample median, and 0 otherwise. ${ }^{6}$ The first dummy captures the deaths of major (i.e., supposedly very popular and beloved) celebrities, which received considerable media attention (632 events) and are more likely to have affected market prices; the second dummy captures the deaths of minor (i.e., not-so-popular) celebrities, which attracted only minor or no media attention (714 events) and, therefore, should not be expected to have swayed the marginal investor's behavior. Figure 1 depicts the frequency distribution of major and minor celebrity deaths by year and reveals that they followed approximately the same pattern over time.

\footnotetext{
${ }^{5}$ Chen (2011), too, examined celebrity deaths, but he crucially ignored this distinction, which may explain why he did not find any evidence of a celebrity-death effect.

${ }^{6}$ I used a two-day window in my main specification because my data set did not allow me to identify the exact time when the public first heard the news about the death of a celebrity. I dealt with non-trading days in the following way: if the market is closed on day $t$ (e.g., Sunday) and open on day $t+1$ (Monday), the dummy takes value 1 only on day $t+1$; if the market is open on day $t$ (e.g., Friday) and closed on day $t+1$ (Saturday), then the dummy takes value 1 only on day $t$; if the market is closed both on day $t$ and $t+1$ (e.g., Saturday and Sunday), then I assumed the celebrity death had no impact on the stock market. The rationale is that investor mood changes are short-lived, and consequently an event that affects people's moods on a Saturday is unlikely to influence their investment decisions when the market reopens the following Monday. The results are robust to alternative specifications, as I show in section A4 of the online Appendix. Lastly, when multiple celebrity deaths occurred on the same day, I computed the maximum of the resulting newspaper article counts and I assigned it to that day.
} 


\section{<< Insert Figure 1 here $>>$}

A few concerns need to be addressed regarding this sorting of celebrities. First, one may worry that the results presented later are driven by the popularity proxy described above; to address this concern, in section A4 of the online Appendix I employ an alternative popularity proxy (star rank) that does not rely on newspaper coverage of celebrity deaths, and I show that the results are robust. Second, one may argue that there exist more than two levels of celebrity and that my sorting method is rather crude; to deal with this issue, in section A4 I abandon the two-group classification approach, and I provide evidence that the size of the stock market's response to a celebrity death is increasing in the amount of press coverage that such a death attracts. Third, it is possible that journalistic tastes and editorial priorities change over time and, as a result, the amount of attention that the mass media devote to celebrities may vary over time, which would bias my main celebrity popularity proxy. Figure 2 sheds light on this issue by displaying how the frequency with which the deceased celebrities in the sample were mentioned by the press (in the seven days following their death) varied over time. The solid line is a locally weighted scatterplot smoother (fitted using running-line least square smoothing with a bandwidth equal to $10 \%$ of the data) that captures changing trends in newspaper coverage of celebrity deaths. Unreported tests showed that all the key results of this paper are robust to sorting the celebrities into major and minor after detrending the newspaper coverage data using the smoother in Figure $2 ;{ }^{7}$ as such, the findings are not driven by shifting trends in the press coverage of celebrities. For this reason, in the interest of simplicity, and given that Figure 2 does not reveal any sizeable trend in the data, all the estimates presented in the rest of the paper are based on the basic two-group classification of celebrities that was introduced at the beginning of this section.

\section{<< Insert Figure 2 here $>>$}

\footnotetext{
${ }^{7}$ The results are robust to using a bandwidth of $5 \%$ or $15 \%$. They are also robust to detrending the newspaper coverage data using a linear time trend, a quadratic time trend, or a log-linear time trend in place of the locally weighted scatterplot smoother.
} 


\section{$<$ Insert Table 1 here $>>$}

With regard to the performance of the U.S. stock market, my main data source was the Center for Research in Security Prices (CRSP). More in detail, for the sample period from January 2, 1926 through December 31, 2009, I obtained from CRSP the time series of the equal-weighted and valueweighted returns (including distributions) for the NYSE/AMEX/NASDAQ market combination. Table 1 reports some descriptive statistics. A set of (unreported) augmented Dickey-Fuller tests confirmed that all the continuous variables employed in the empirical analysis are stationary.

\section{Empirical analysis}

\subsection{Baseline model}

All t-tests and all significance levels referred to in this paper are two-tailed, which is in line with the argument that a negative shift in investor mood may have either a positive or a negative effect on stock returns. The starting point of my analysis is a linear model that regresses U.S. equity returns on a constant, a set of lagged returns, and the two celebrity-death dummies of interest:

$$
R_{t}=\alpha+\beta_{1} \text { MajorCeleb }_{t}+\beta_{2} \text { MinorCele }_{t}+\sum_{k=1}^{5} \gamma_{1, k} R_{t-k}+\varepsilon_{t}
$$

where $R_{t}$ measures the CRSP equal-weighted (or value-weighted) log return between day $t-1$ and day $t$, $\alpha$ is the intercept, and the remaining variables are as previously defined. The equation contains five lags of the dependent variable to control for serial correlation in returns. I estimated the model's parameters by OLS, and to conduct statistical inference I computed Newey-West (1987) heteroskedasticity and serial correlation robust standard errors (up to 5 lags). Table 2 displays the results for the equal-weighted and value-weighted returns in columns (1) and (2), respectively. The estimated sign and size of the coefficient on MajorCeleb are consistent across the two CRSP series. 
Other things equal, the death of a popular HWF celebrity that attracts substantial press coverage is accompanied by an increase in stock returns. In the case of the value-weighted returns, the immediate response $\left(\beta_{1}\right)$ is an increase of 8 basis points, and the dynamic marginal effect at one lag $\left(\beta_{1}+\gamma_{1,1} \times \beta_{1}\right)$ is an increase of 9 basis points, for a cumulative effect of about 17 basis points per death over a twoday window (recall that MajorCeleb takes value 1 on day $t$ and $t+1$ if a major celebrity dies on day $t$ ). Coefficient $\beta_{1}$ is statistically different from zero for both return series ( $\mathrm{p}$-values $=0.010$ and 0.008 ); the sign of the coefficient is consistent with the hypothesis that the wave of negative sentiment caused by the death of a popular celebrity strengthens the marginal investor's risk-taking propensity, increases the net demand for risky assets, and raises equity returns.

Conversely, the estimated coefficient on MinorCeleb is economically negligible and statistically indistinguishable from zero. In other words, as expected, there is no evidence that the deaths of minor celebrities influence aggregate investor sentiment and equity prices. A test of equality of coefficients revealed that the coefficient on MajorCeleb is statistically different from the one on MinorCeleb at standard significance levels ( $\mathrm{p}$-values $=0.025$ and 0.017 ). In summary, the picture that emerges from this preliminary model provides initial support for hypothesis $H 1$.

\section{$<<$ Insert Table 2 here $>>$}

A detailed discussion of the practical importance of these results is deferred to section 7, where I provide evidence that the magnitude of the celebrity-death effect compares favorably with the effect sizes of sentiment studies published in leading finance journals and is large enough that a trading strategy based upon it would be profitable after transaction costs are accounted for. For the moment, to set the stage for a subsequent assessment of the economic significance of this effect, I would like to bring the reader's attention to the fact that its size is approximately five times the size of the unconditional mean daily value-weighted return (3.4 basis points). 


\subsection{Seasonalities}

One may wonder whether the results described above are caused by common temporal patterns in the dynamics of stock returns and human mortality rates. Indeed, finance scholars have detected several seasonal patterns in the behavior of the stock market. Bouman and Jacobsen (2002), for instance, found evidence that equity returns are "significantly lower during the May-October period than during the remainder of the year". Kamstra et al. (2003) argued that "returns are at their lowest in September and then they peak shortly after winter solstice”. Ko et al. (1997), among others, documented that stock returns vary by day of the week. Rozeff and Kinney (1976) found that returns are higher in January than in other months. Lakonishok and Smidt (1988) reported that returns are unusually high at the turn of the month and immediately prior to major holidays, while Liano et al. (1992) documented that post-holiday returns are unusually low. Levy and Yagil (2012) reported that stock returns are unusually low in week 43 (from October 22 through October 28) and unusually high in week 44 (from October 29 through November 4), and Kamstra et al. (2000) provided evidence that returns are lower on the trading days that follow daylight saving time changes than on regular days.

Analogously, social scientists have documented the existence of seasonal patterns in mortality rates. For instance, overall mortality rates increase in the winter (Reichert et al., 2004), and "deaths from natural causes spike around Christmas and New Year" (Phillips et al., 2010). There is also evidence that suicides tend to peak on Mondays, in the spring, and in early summer months (e.g., Massing and Angermeyer, 1985). Motor vehicle fatalities, instead, tend to peak in the summer months and during holidays (Bollen, 1983). To control for these potentially confounding effects, I augmented model [1] with an additional set of covariates, as follows:

$$
\begin{aligned}
R_{t}= & \alpha+\beta_{1} \text { MajorCeleb }_{t}+\beta_{2} \text { MinorCeleb }_{t}+\sum_{k=1}^{5} \gamma_{1, k} R_{t-k}+\sum_{k=1}^{6} \delta_{1, k} D_{k, t}+\delta_{2} \text { PreH }_{t}+\delta_{3} \text { Post }_{t} \\
& +\delta_{4} \text { TOM }_{t}+\delta_{5} \text { January }_{t}+\delta_{6} \text { SMGA }_{t}+\delta_{7} \text { Week } \text { S }_{t}+\delta_{8} \text { Week } 44_{t}+\delta_{9} D S T_{t}+\varepsilon_{t}
\end{aligned}
$$


where $D_{k}$ is a dummy that takes value 1 on the $k^{\text {th }}$ day of the week, and PreH and Post $H$ are two dummies that take value 1 on the trading day that precedes and follows each major holiday (New Year's day, Martin Luther King’s day, President's day, Good Friday, Memorial day, Independence day, Labor day, Thanksgiving day, and Christmas day), respectively. ${ }^{8}$ TOM takes value 1 on the first three trading days and the last trading day of each month, January takes value 1 if the trading day is in January, and SMGA takes value 1 on trading days between November 1 and April 30. Week43 takes value 1 between October 22 and October 28 of each year, and Week44 takes value 1 between October 29 and November 4 of each year. Lastly, DST takes value 1 on the trading day that immediately follows a daylight saving time change in the United States.

Table 2 shows the estimates generated by fitting model [2] in columns (3) and (4). The signs of the coefficients on the seasonal control variables are all consistent with prior research, but only about half of them are statistically significant at conventional levels for both return series (pre-holiday, postholiday, turn of the month, week 44, and daylight saving time). For example, the coefficient on the preholiday dummy indicates that stock returns are about 22-32 basis points higher on trading days that immediately precede major holidays than on regular days. More importantly, adding all these control variables has virtually no impact on the coefficients on the two celebrity-death dummies of interest. The immediate response $\left(\beta_{1}\right)$ to the death of a major celebrity is now a 9-basis-point increase in stock returns, and the dynamic marginal effect at one lag $\left(\beta_{1}+\gamma_{1,1} \times \beta_{1}\right)$ is an increase of about 9 basis points, for a cumulative effect of 18 basis points per death. Coefficient $\beta_{1}$ is statistically different from zero at the $1 \%$ significance level, the coefficients on MajorCeleb and MinorCeleb are statistically different from each other at standard significance levels ( $\mathrm{p}$-values $=0.014$ and 0.014$)$, and the null hypothesis that the deaths of minor celebrities have no effect on stock returns cannot be rejected.

\footnotetext{
${ }^{8}$ Saturday trading sessions were discontinued on June 1, 1952.
} 


\subsection{Liquidity, market frictions, and behavioral factors}

To deal with the influence of liquidity and other possible market frictions, I followed Tetlock (2007) and added to model [2] a variable measuring the detrended NYSE daily (log) share volume and a variable measuring the detrended squared residual of the CRSP returns series. ${ }^{9,10}$ The resulting regression equation is as follows:

$$
\begin{aligned}
& R_{t}=\alpha+\beta_{1} \text { MajorCeleb }_{t}+\beta_{2} \text { MinorCeleb }_{t}+\sum_{k=1}^{5} \gamma_{1, k} R_{t-k}+\sum_{k=1}^{6} \delta_{1, k} D_{k, t}+\delta_{2} \text { PreH }_{t}+\delta_{3} \text { Post }_{t}+\delta_{4} \text { TOM }_{t} \\
& +\delta_{5} \text { January }_{t}+\delta_{6} \text { SMGA }_{t}+\delta_{7} \text { Week } 3_{t}+\delta_{8} \text { Week } 4_{t}+\delta_{9} \text { DST }_{t}+\sum_{k=1}^{5} \emptyset_{1, k} \text { Vlm }_{t-k}+\sum_{k=1}^{5} \emptyset_{2, k} \text { Vol }_{t-k}+\varepsilon_{t}
\end{aligned}
$$

\section{<< Insert Table 3 here $>>$}

where Vlm measures the detrended NYSE log share volume, and Vol measures the detrended CRSP squared return residual. To save space, columns (1) and (2) of Table 3 show only part of the regression output. The results suggest that liquidity has a positive impact on stock returns, which is consistent with previous studies (e.g. Karpoff, 1987), as the coefficient on the 1-day-lagged liquidity proxy is positive and statistically significant at the $1 \%$ level. With regard to past return volatility, the coefficient on the 2-day-lagged $\mathrm{Vol}$ variable is significantly positive and the one on the 5-day-lagged Vol variable is significantly negative. This said, the signs, sizes, and statistical significance of the coefficients on the two celebrity-death dummies are virtually unchanged compared to Table 2 .

Previous behavioral finance research has documented that various environmental factors affect investor mood and equity returns. For example, Kamstra et al. (2003) found that stock returns follow a

\footnotetext{
${ }^{9}$ I collected the share volume data from the NYSE's website (https://www.nyse.com/data/transactions-statistics-data-library). I filled in 24 missing observations by using linear interpolation from adjacent trading days. Following a methodology along the lines of Campbell, Grossman and Wang (1993) and Tetlock (2007), I then detrended the data by subtracting the 42-day (i.e., about two calendar months) moving average of log daily share volumes from the log share volume on day $t$. The results were nearly identical when using the 63-day or 84-day moving average.

${ }^{10}$ After demeaning each CRSP return series to generate a residual, I squared the residual and I subtracted the 42-day moving average of past squared residuals. The results were virtually identical when using the 63-day or 84-day moving average.
} 
seasonal cycle that is in line with the prevalence of the so-called seasonal affective disorder (SAD). Yuan et al. (2006) proposed a link between equity returns and the lunar cycle, and Krivelyova and Robotti (2003) argued that geomagnetic storms have a negative effect on the stock market, allegedly through their influence on people's mood. Since the medical literature has documented that similar environmental factors influence human death rates, one may wonder whether the anomaly described up to this point is caused by the simultaneous impacts that environmental forces have on the stock market and (celebrity) death rates. For instance, Jones and Jones (1977) proposed a link between suicides and the lunar cycle, Lambert et al. (2003) found that suicide rates follow a seasonal pattern consistent with the amount of sunlight, and Villoresi et al. (1998) detected a positive relationship between geomagnetic disturbances and myocardial infarction rates. To deal with these potentially confounding factors, I augmented model [3] as follows:

$$
\begin{aligned}
& R_{t}=\alpha+\beta_{1} \text { MajorCeleb }_{t}+\beta_{2} \text { MinorCeleb }_{t}+\sum_{k=1}^{5} \gamma_{1, k} R_{t-k}+\sum_{k=1}^{6} \delta_{1, k} D_{k, t}+\delta_{2} \text { PreH }_{t}+\delta_{3} \text { Post }_{t}+\delta_{4} \text { TOM }_{t} \\
& +\delta_{5} \text { January }_{t}+\delta_{6} \text { SMGA }_{t}+\delta_{7} \text { Week } \text { S }_{t}+\delta_{8} \text { Week } 4_{t}+\delta_{9} D S T_{t}+\sum_{k=1}^{5} \emptyset_{1, k} \text { Vlm }_{t-k}+\sum_{k=1}^{5} \emptyset_{2, k} \text { Vol }_{t-k} \\
& +\varphi_{1} \text { SADOR }_{t}+\varphi_{2} \text { FullMoon }_{t}+\varphi_{3} \text { NewMoon }_{t}+\varphi_{4} \text { GMStorm }_{t}+\varepsilon_{t}
\end{aligned}
$$

where $S A D O R$ is the SAD onset/recovery proxy that Kamstra et al. (2015) employed to track changes in investor risk aversion across the seasons. ${ }^{11}$ FullMoon (NewMoon) is a dummy that takes value 1 from day $t-3$ through day $t+3$, and 0 otherwise, where $t$ is a full (new) moon date. GMStorm is a dummy that proxies for geomagnetic storms and takes value 1 on day $t$ and $t+1$ if the $\mathrm{c} 9$ geomagnetic index, which ranges from 0 to 9 , is greater than or equal to 6 on day $t$, and 0 otherwise.

Table 3 displays the relevant regression output in columns (3) and (4). The coefficient on the seasonal affective disorder proxy is negative, which is consistent with Kamstra et al.'s (2003) claim

\footnotetext{
${ }^{11}$ Lisa Kramer kindly provided the relevant data (http://www.lisakramer.com/data.html).
} 
that the rise (decrease) in risk aversion during the fall (winter) reduces (increases) investors' demand for risky assets and compresses (raises) stock returns. Yet, only in the case of the equal-weighted returns is this coefficient statistically different from zero at the $10 \%$ level. The coefficients on the two moon cycle dummies are negligible in size and statistically indistinguishable from zero. Lastly, the coefficient on GMStorm is negative and significant at the $10 \%$ level for the equal-weighted returns, which is in line with Krivelyova and Robotti's (2003) finding that large disturbances in the Earth's magnetic field are accompanied by unusually low stock returns. Despite the addition of the new controls, the regression output confirms that the deaths of major celebrities are accompanied by unusually high stock returns, whereas there is no evidence of a relationship between stock returns and the deaths of minor celebrities.

\subsection{Additional controls, robustness tests, and ancillary hypotheses}

Additional analyses are discussed in the online Appendix. In brief, even after controlling for the release of economic news, there is evidence that major celebrity deaths are followed by an abnormal $0.16 \%$ increase in stock returns; the effect is robust to a variety of checks and specification changes. I also provide evidence that (1) the size of this effect is increasing in the amount of press coverage received by a deceased celebrity (hypothesis H2), (2) expected celebrity deaths produce weaker market reactions than unexpected ones (hypothesis H3), and (3) the market's reaction to the death of a popular celebrity is stronger $(+0.40 \%)$ when market-level uncertainty is high (hypothesis $H 4)$. With regard to the cross section of stock returns, the additional analyses show that the celebrity-death effect is stronger for stocks that are harder to value and more difficult to arbitrage (hypothesis H5), and, consistent with local trading bias, it is also stronger $(+0.26 \%)$ for stocks headquartered in the city where the celebrity died. Lastly, to shed light on the underlying mechanism, in section A7 of the online Appendix I provide 
direct evidence that major celebrity deaths promote risk-taking behavior by documenting that lottery ticket sales increase in response to such events.

\section{Discussion}

The evidence presented up to this point raises two issues that deserve attention. Firstly, is the size of the celebrity-death effect practically relevant? Secondly, how do the results of this study compare with the findings of previous behavioral finance studies on investor sentiment? Answering the first question requires identifying a target audience and a suitable benchmark. Target audiences relevant to this study are academics, practitioners, and the public. One way to determine whether an effect size is considered economically significant by the finance academic community is to compare it with the typical size of the effects reported in studies published in leading finance journals. I therefore searched through all articles published in The Journal of Finance, The Journal of Financial Economics, and the Review of Financial Studies to identify sentiment studies that used data at a daily frequency. Figure 3 displays the point estimates and $95 \%$ confidence intervals of the sentiment effects that the search returned. To facilitate comparisons, all effects are reported in absolute value. What emerges is that the size of the celebrity-death effect (top row) is as big as that of the effects appearing alongside it in the figure, and the precision of the effect estimate is similar to that found in studies based on discrete mood-inducing events (Edmans et al., 2007; Kaplanski and Levy, 2010).

\section{$<<$ Insert Figure 3 here $>>$ $<<$ Insert Table 4 here $>>$}

As for practitioners, if one adopts the rather narrow view that their interest in a finding is primarily driven by whether it may affect their investment returns, then the implication is that a stock market anomaly may be of interest to institutional investors if it is large enough, relative to typical 
trading costs, to form the basis of a profitable trading strategy. Table 4 shows the results of a simple strategy based on celebrity deaths with and without perfect foresight and with and without transaction costs. The strategy involves alternating between a long position in the risk-free asset (the status quo) and a long position in S\&P 500 futures (when a major celebrity dies); for example, the version based on perfect foresight assumes that, when a major celebrity dies on day $t$, the portfolio is invested in S\&P 500 futures at the end of day $t-1$, and the futures position is liquidated at the end of day $t+1$. The sample covers the period from April 23, 1982, when the CME introduced the S\&P 500 futures contract, through December 31, 2009. ${ }^{12}$ The S\&P 500 index was used as a proxy for the market portfolio in the estimation of the strategy's CAPM alpha. With perfect foresight of celebrity deaths, no transaction costs, and a 20\% margin level (Panel A) the strategy's mean raw return is $14.38 \%$ per year, and its annualized alpha is $8.05 \%$. If no perfect foresight is assumed and transaction costs are included (Panel D), given a $20 \%$ margin level the strategy's mean raw return is $8.36 \%$ per year, and its annualized alpha is $2.97 \% .{ }^{13}$ Given that the median hedge fund's annualized CAPM alpha was 3.43\% between 1994 and 2012 (Agarwal et al., 2018), the results presented in the table suggest that the celebrity-death effect is as big as other stock market anomalies that institutional investors try to exploit.

Lastly, as far as the public is concerned, to put things in perspective it is useful to compare the size of this behavioral effect to that of the effects caused by scheduled macroeconomic announcements, to which the public seems to pay close attention as they are widely covered by the media (e.g. Birz and Lott, 2011). Flannery and Protopapadakis (2002) estimated that the announcements that have the largest impact on U.S. stock returns are the ones about PPI, CPI, and M1, in which cases a one-

\footnotetext{
${ }^{12}$ I obtained the series of the S\&P 500 futures contract's settlement price from Datastream (code: ISPCS00).

${ }^{13}$ On November 3, 1997, the CME reduced the multiplier of the S\&P 500 futures contract from $\$ 500$ to $\$ 250$ and increased its tick size from 0.05 to 0.10 index points. Transaction costs are based on the following assumptions: the bid-ask spread of the S\&P 500 futures contract is 0.05 index points between April 1982 and December 1987 (Stoll and Whaley, 1990), 0.06 index points between January 1988 and October 1997 (Bollen et al., 2003), and 0.37 index points (i.e. 0.028\%) between November 1997 and December 2009 (Smimou, 2017), and the commission fees are \$25 per contract per trade (including exchange fees and floor brokerage) for institutional investors (Huang and Stoll, 1998).
} 
standard-deviation surprise relative to analysts' consensus forecast causes an abnormal change in returns of $0.153 \%, 0.136 \%$, and $0.063 \%$, respectively. As such, if anything, the effect of a major celebrity death on stock returns is at least as economically relevant as that of a substantial shock to macroeconomic fundamentals. To some extent, the frequency of these events is also analogous, as the value of a macro indicator is typically released twelve times per year, while major celebrity deaths have occurred with a frequency of 10.2 per year since the construction of the HWF. These three lines of argument lead me to conclude that the effect analyzed in this study is economically meaningful and worthy of investigation.

Moving on to the second issue, while the results that I present are consistent with what Andrade (2005) called the dynamic affect regulation theories, they appear to be inconsistent with the so-called static affect evaluation theories and a couple of notable behavioral finance studies that found evidence in favor of the latter (Hirshleifer and Shumway, 2003; Edmans et al., 2007). Here I present two lines of reasoning that may help reconcile these seemingly conflicting findings. Firstly, as Pittman (1993) put it, "not all 'negative' moods are the same nor are they always likely to produce the same effects". With regard to this point, Raghunathan and Pham (1999) observed that sadness sways individuals toward high-risk/high-reward choices, while anxiety (a different type of negative mood) tilts them toward lowrisk/low-reward options. Cohen-Charash et al. (2013) found that activated unpleasant trader mood (e.g., furious, frustrated, rage, etc) predicts NASDAQ declines, while deactivated unpleasant mood (e.g., feel bad, gloomy, not happy, etc) predicts NASDAQ rises. As a result, a possible interpretation is that Edmans et al. (2007) found that national teams' losses in international competitions lead to stock market declines because such losses stir up feelings of anger and frustration in sports fans, whereas the present study found that celebrity deaths lead to market rises because such deaths cause feelings of sadness in the public. Yet, research on the contrasting effects of negative moods of different valence is still in its early stages, and the exact mechanisms at work have not been fully understood. 
Secondly, it is not yet well established whether shifts in investor mood and risk appetite are responsible for the empirical patterns documented by Hirshleifer and Shumway (2003) and Edmans et al. (2007). Edmans et al. (2007) conjectured that national teams' losses are followed by abnormally low stock returns because the former have a negative impact on investor mood. However, Bernhardt et al. (1998) found that watching one's favorite sports teams win or lose "has physiological consequences that extend beyond changes in mood and self-esteem"; more specifically, they observed that "mean testosterone level increased in the fans of winning teams and decreased in the fans of losing teams". Since the literature suggests that levels of testosterone correlate positively with financial risk taking (Apicella et al., 2015), it remains to be seen whether investor mood is the mediating factor in the relationship between national teams' losses and stock returns. Analogously, Hirshleifer and Shumway (2003) speculated that decreased cloud cover is accompanied by abnormally high stock returns because sunshine exerts a positive impact on investor mood. However, as Glimcher and Tymula (2017) highlighted, according to the meteorology literature "cloud coverage alone has little to do with the light exposure at the earth surface level", and "[u]nder many circumstances increases in cloud cover can actually increase surface luminance" (i.e. the "amount of light that falls on the surface of the earth"). In their study, Glimcher and Tymula (2017) found that exposure to more sunlight (luminance) leads to less risk taking. As such, and given that the literature argues that it is light exposure (as opposed to cloud coverage) that influences mood, it is far from obvious whether the effect that Hirshleifer and Shumway (2003) documented is mediated by changes in investor mood and risk-taking behavior. In conclusion, the results presented in this study are better seen as complementary to (rather than in conflict with) those found in some earlier behavioral finance studies, and more work is needed to disentangle the effects of investor mood (or types of mood) from those of mood-related factors.

\section{Concluding remarks}


This study contributes both to the ongoing discussion on the relevance of investor sentiment to asset pricing and to the local trading bias literature. Motivated by the evidence offered by media communication and psychology scholars, according to which large numbers of individuals develop a psychological attachment to celebrities and may experience emotional distress in response to their death, I investigated the reactions of the U.S. stock market to the deaths of entertainers inducted into the HWF. I documented that, other things the same, the death of a major celebrity is immediately followed by an abnormal $0.16 \%$ increase in stock returns. This effect is economically meaningful, especially when compared with the cost of trading S\&P 500 futures and with the findings of sentiment studies published in leading finance journals.

The results are consistent with the interpretation that celebrity deaths have a negative impact on people's mood, which strengthens unsophisticated investors' risk-taking propensity and increases their net demand for risky assets, ultimately leading to higher equity returns. Several key pieces of evidence support this view. First, celebrity deaths are exogenous events that have no direct (macro)economic impact. Second, the dynamic affect regulation theories (Andrade, 2005) provide a clear mechanism as to why individuals experiencing a negative mood, sadness in particular, tend to favor high-risk/highreward choices. Third, the celebrity-death effect is stronger for stocks headquartered in the city where the celebrity died. Fourth, lottery sales increase following major celebrity deaths, which provides direct evidence that changes in individuals' risk-taking behavior represent the likely mechanism behind the observed phenomenon.

Future investigations on this subject may expand the analysis presented here using data from other countries where celebrity culture has flourished. Jansen's (2016) work represents a first step in this direction; he replicated an earlier version of this study using data about the deaths of a sample of British, Dutch, and German celebrities and found results analogous to mine. This is very encouraging for the validity of the hypothesis proposed and tested here. 


\section{References}

Agarwal, V., T. C. Green, and H. Ren, 2018. Alpha or beta in the eye of the beholder: What drives hedge fund flows?, Journal of Financial Economics 127(3), 417-434.

Andrade, E. B., 2005. Behavioral consequences of affect: Combining evaluative and regulatory mechanisms, Journal of Consumer Research 32, 355-362.

Apicella, C. L., J. M. Carré, and A. Dreber, 2015. Testosterone and economic risk taking: a review, Adaptive Human Behavior and Physiology 1(3), 358-385.

$\mathrm{Au}, \mathrm{K}$., F. Chan, D. Wang, and I. Vertinsky, 2003. Mood in foreign exchange trading: Cognitive processes and performance, Organizational Behavior and Human Decision Processes 91, 322-338.

Baker, M., and J. Wurgler, 2006. Investor sentiment and the cross-section of stock returns, Journal of Finance 61, 1645-1680.

Bernhardt, P. C., J. M. Dabbs Jr, J. A. Fielden, and C. D. Lutter, 1998. Testosterone changes during vicarious experiences of winning and losing among fans at sporting events, Physiology \& Behavior 65(1), 59-62.

Birz, G., and J. R. Lott, 2011. The effect of macroeconomic news on stock returns: New evidence from newspaper coverage, Journal of Banking and Finance 35(11), 2791-2800.

Bodnaruk, A., 2009. Proximity always matters: Local bias when the set of local companies changes, Review of Finance 13(4), 629-656.

Bollen, K. A., 1983. Temporal variations in mortality: a comparison of U.S. suicides and motor vehicle fatalities, 1972-1976, Demography 20(1), pp. 45-59.

Bollen, N. P., T. Smith, and R. E. Whaley, 2003. Optimal contract design: For whom?, Journal of Futures Markets: Futures, Options, and Other Derivative Products 23(8), 719-750.

Bouman, S., and B. Jacobsen, 2002. The Halloween indicator," Sell in May and go away": Another puzzle, The American Economic Review 92(5), 1618-1635.

Bowlby, J., 1998. Loss: Sadness and depression. Random House.

Brown, W. J., M. D. Basil, and M. C. Bocarnea, 2003. Social Influence of an International Celebrity: Responses to the Death of Princess Diana, Journal of Communication 53(4), 587-605.

Bruyneel, S., S. Dewitte, P. H. Franses, and M. G. Dekimpe, 2005. Why Consumers Buy Lottery Tickets When The Sun Goes Down On Them, Working paper, Erasmus University Rotterdam.

Campbell, J., Y., S. J. Grossman, and J. Wang, 1993. Trading volume and serial correlation in stock returns, Quarterly Journal of Economics 108, 905-939.

Caughey, J., 1984. Imaginary social worlds. University of Nebraska Press.

Chen, Z., 2011. The Effects of Sudden Celebrity Deaths on the US Stock Market. In: International Conference on Advances in Education and Management (pp. 441-447). Springer Berlin Heidelberg.

Cheng, A. T. A., K. Hawton, C. T. C. Lee, and T. H. H. Chen, 2007. The influence of media reporting of the suicide of a celebrity on suicide rates: a population-based study, International Journal of Epidemiology 36(6), 1229-1234.

Chuang, S. C., and C. Kung, 2005. The effects of emotions in risk-taking, Journal of American Academy of Business 6(2), 113-118.

Cohen-Charash, Y., C. A. Scherbaum, J. D. Kammeyer-Mueller, and B. M. Staw, 2013. Mood and the market: can press reports of investors' mood predict stock prices?, PloS one 8(8).

Conte, A., M. V. Levati, and C. Nardi, 2018. Risk preferences and the role of emotions, Economica 85, 305-328.

Coval, J. D., and T. J. Moskowitz, 1999. Home bias at home: Local equity preference in domestic portfolios, The Journal of Finance 54(6), 2045-2073. 
Da, Z., J. Engelberg, and P. Gao, 2015. The sum of all FEARS investor sentiment and asset prices, The Review of Financial Studies, 28(1), 1-32.

Edmans, A., D. Garcia, and Ø. Norli, 2007. Sports sentiment and stock returns, The Journal of Finance 62(4), 1967-1998.

Elliott, A., 1998. Celebrity and political psychology: remembering Lennon, Political Psychology 19(4), 833-852.

Flannery, M. J., and A. A. Protopapadakis, 2002. Macroeconomic factors do influence aggregate stock returns, The Review of Financial Studies 15(3), 751-782.

Gamson, J., 1994. Claims to fame: celebrity in contemporary America. University of California Press.

Garcia, D., 2013. Sentiment during recessions, The Journal of Finance, 68(3), 1267-1300.

Gibson, M., 2007a. Death and mourning in technologically mediated culture, Health sociology review $16,415-424$.

Gibson, M., 2007b. Some thoughts on celebrity deaths: Steve Irwin and the issue of public mourning, Mortality 12(1), 1-3.

Giratikanon, T., J. Katz, D. Leonhardt, and K. Quealy. "Which team do you cheer for? An N.B.A. fan map" The Upshot, The New York Times Company, 19 October 2014, https://www.nytimes.com/interactive/2014/05/12/upshot/12-upshot-nba-basketball.html.

Glimcher, P. W., and A. Tymula, 2017. Let the sunshine in? The effects of luminance on economic preferences, choice consistency and dominance violations, PloS one 12(8).

Goldenberg, R., 2018. Life after death on Wikipedia, The Pudding. Retrieved from https://pudding.cool/2018/08/wiki-death/.

Hall, C. W., and R. A. Reid, 2009. Adolescent bereavement over the deaths of celebrities. In: David, E., D. E. Balk, and C. A. Corr, 2009. Adolescent encounters with death, bereavement, and coping (pp. 237-252). Springer Publishing Company.

Hirshleifer, D., and T. Shumway, 2003. Good day sunshine: Stock returns and the weather, The Journal of Finance 58(3), 1009-1032.

Horton, D., and R. R. Wohl, 1956. Mass communication and parasocial interaction: Observations on intimacy at a distance, Psychiatry 19, 215-229.

Huang, R. D., and H. R. Stoll, 1998. Is it time to split the S\&P 500 futures contract?, Financial Analysts Journal 54(1), 23-35.

Isen, A. M., 1984. Toward understanding the role of affect in cognition. In: R. S. Wyer and T. K. Srull (Eds.), Handbook of social cognition (pp. 179-236), Hillsdale, NJ: Erlbaum.

Jansen, H., 2016. Celebrity deaths and social mood, Master's thesis, Radboud University, Netherlands. Retrieved from https://theses.ubn.ru.nl/handle/123456789/3148.

Jiang, G., C. M. C. Lee, and Y. Zhang, 2005. Information uncertainty and expected returns, Review of Accounting Studies 10, 185-221.

Johnson, E. J., and A. Tversky, 1983. Affect, generalization and the perception of risk, Journal of personality and social psychology 45, 20-31.

Jones, P. K., and S. L. Jones, 1977. Lunar association with suicide, Suicide and Life-Threatening Behavior 7(1), 31-9.

Kamstra, M. J., L. A. Kramer, and M. D. Levi, 2000. Losing sleep at the market: The daylight saving anomaly, The American Economic Review 90(4), 1005-1011.

Kamstra, M. J., L. A. Kramer, and M. D. Levi, 2003. Winter blues: a SAD stock market cycle, American Economic Review 93, 324-341.

Kamstra, M. J., L. A. Kramer, and M. D. Levi, 2015. Seasonal Variation in Treasury Returns, Critical Finance Review 4(1), 45-115. 
Kaplanski, G., and H. Levy, 2010. Sentiment and stock prices: The case of aviation disasters, Journal of Financial Economics 95(2), 174-201.

Karpoff, J. M., 1987. The relation between price changes and trading volume: A survey, Journal of Financial and Quantitative Analysis 22(1), 109-126.

Keller, J., 2011. Google Shuts Down Newspaper Archive Project. The Atlantic (May 20). Retrieved from https://www.theatlantic.com/technology/archive/2011/05/google-shuts-down-newspaper-archiveproject/239239/.

Kliger, D., and O. Levy, 2003. Mood-induced variation in risk preferences, Journal of Economic Behavior and Organization 52, 573-584.

Ko, W., L. Yuming, and J. Erickson, 1997. A New Look at the Monday Effect, The Journal of Finance 52(5), 2171-2186.

Kostopoulos, D. and S. Meyer, 2020. Google Search Volume and Individual Investor Trading, Journal of Financial Markets, In Press.

Krivelyova, A. and C. Robotti, 2003. Playing the field: geomagnetic storms and the stock market, Working paper No. 2003-5b, Federal reserve bank of Atlanta.

Kumar, A. 2009. Hard-to-Value Stocks, Behavioral Biases, and Informed Trading, Journal of Financial and Quantitative Analysis 44(6), 1375-1401.

Kumar, A., and C. Lee, 2006. Retail investor sentiment and return comovements, The Journal of Finance 61(5), 2451-2486.

Kurzman, C., C. Anderson, C. Key, Y. O. Lee, M. Moloney, A. Silver, and M. W. Van Ryn, 2007. Celebrity status, Sociological Theory 25(4), 347-367.

Lakonishok, J., and S. Smidt, 1988. Are seasonal anomalies real? A ninety-year perspective, Review of Financial Studies 1(4), 403-425.

Lambert, G., C. Reid, D. Kaye, G. Jennings, and M. Esler, 2003. Increased suicide rate in the middleaged and its association with hours of sunlight, American Journal of Psychiatry 160(4), 793-795.

Lee, M. J., 1985. From rivalry to hostility among sports fans, Quest 37(1), 38-49.

Leff, L., 1997. Hemingway and his conspirators: Hollywood, scribners, and the making of American celebrity culture, Rowman \& Littlefield Pub Inc.

Lerner, J. S., Y. Li, P. Valdesolo, and K. S. Kassam, 2015. Emotion and decision making, Annual Review of Psychology 66, 799-823.

Levy, M., 1979. Watching television news as parasocial interaction, Journal of Broadcasting 23, 69-80.

Levy, O., and I. Galili, 2008. Stock purchase and the weather: Individual differences, Journal of Economic Behavior \& Organization 67(3), 755-767.

Levy, T., and J. Yagil, 2012. The week-of-the-year effect: Evidence from around the globe, Journal of Banking and Finance 36(7), 1963-1974.

Liano, K., P. H. Marchand, and G. C. Huang, 1992. The holiday effect in stock returns: evidence from the OTC market, Review of Financial Economics 2(1), 45-54.

Lindemann, E., 1944. Symptomatology and management of acute grief, American Journal of Psychiatry 101(2), 141-148.

Loewenstein, G., and J. S. Lerner, 2003. The role of affect in decision making. In: R. Davidson, H. Goldsmith, and K. Scherer (Eds.), Handbook of affective science (pp. 619-642), Oxford, England: Oxford University Press.

Loughran, T., and P. Schultz, 2004. Weather, stock returns, and the impact of localized trading behavior, Journal of Financial and Quantitative Analysis 39(2), 343-364.

Malkinson, R., 2001. Cognitive-Behavioral Therapy of Grief: A Review and Application, Research on Social Work Practice 11(6), 671-698. 
Massing, W., and M. C. Angermeyer, 1985. The monthly and weekly distribution of suicide, Social Science \& Medicine 21(4), 433-441.

Matheson, V. A., and R. A. Baade, 2004. 'Death effect' on collectible prices, Applied Economics 36, 1151-1155.

Mittal, V., and W. T. Ross Jr., 1998. The impact of positive and negative affect and issue framing on issue interpretation and risk taking, Organizational Behavior and Human Decision Processes 76, 298324.

Morris, W. N., and N. P. Reilly, 1987. Toward the self-regulation of mood: Theory and research, Motivation and Emotion 11, 215-249.

Newey, W. K., and K. D. West, 1987. A simple, positive semi-definite, heteroskedasticity and autocorrelation consistent covariance matrix, Econometrica 55(3), 703-708.

Phillips, D., G. E. Barker, and K. M. Brewer, 2010. Christmas and New Year as risk factors for death, Social Science \& Medicine 71(8), 1463-1471.

Pittman, T. S., 1993. Control motivation and attitude change, In: G. Weary, F. Gleicher, and K. Marsh (Eds), Control motivation and social cognition (pp. 157-175), Springer, New York.

Raghunathan, R., and M. T. Pham, 1999. All negative moods are not equal: Motivational influences of anxiety and sadness on decision making, Organizational Behavior and Human Decision Processes 79, 56-77.

Rambova, N., 2009. Rudolph Valentino: A Wife's Memories of an Icon. 1921 PVG Publishing.

Rando, T. A., 1986. A comprehensive analysis of anticipatory grief: Perspectives, processes, promises, and problems. In: Rando, T. A., Loss and Anticipatory Grief (pp. 1-36), Lexington Books, Washington DC.

Reichert, T. A., L. Simonsen, A. Sharma, S. A. Pardo, D. S. Fedson, and M. A. Miller, 2004. Influenza and the Winter Increase in Mortality in the United States, 1959-1999, American Journal of Epidemiology 160(5), 492-502.

Rozeff, M. S., and W. R. Kinney, 1976. Capital market seasonality: The case of stock returns, Journal of financial economics 3(4), 379-402.

Sanderson, J., and P. H. Cheong, 2010. Tweeting Prayers and Communicating Grief Over Michael Jackson Online, Bulletin of Science, Technology \& Society 30(5), 328-340.

Schultz, P., 2003. Who Makes Markets?, Journal of Financial Markets 6, 49-72.

Smimou, K., 2017. Does gold Liquidity learn from the greenback or the equity?, Research in International Business and Finance 41, 461-479.

Stever, G. S., 2010. Fan Behavior and Lifespan Development Theory: Explaining Para-social and Social Attachment to Celebrities, Journal of Adult Development 18(1), 1-7.

Stoll, H. R., and R. E. Whaley, 1990. The dynamics of stock index and stock index futures returns, Journal of Financial and Quantitative analysis 25(4), 441-468.

Tetlock, P., 2007. Giving content to investor sentiment: the role of media in the stock market, The Journal of Finance 62(3), 1139-1168.

Turner, G., 2004. Understanding celebrity, Publisher: SAGE.

Villoresi, G., N. G. Ptitsyna, M. I. Tiasto, and N. Iucci, 1998. Myocardial infarct and geomagnetic disturbances: analysis of data on morbidity and mortality, Biofizika 43(4), 623-31.

Yuan, K., L. Zheng, and Q. Zhu, 2006. Are investors moonstruck? Lunar phases and stock returns, Journal of Empirical Finance 13, 1-23.

Zhu, N., 2002. The Local Bias of Individual Investors, Working Paper, Yale University.

Zillmann, D., 1988. Mood management: Using entertainment to full advantage. In: Donohew, L., and H. E. Sypher (Eds.), Communication, social cognition, and affect (pp. 147-171), Hillsdale, NJ: Erlbaum. 
(A) Major celebrity deaths

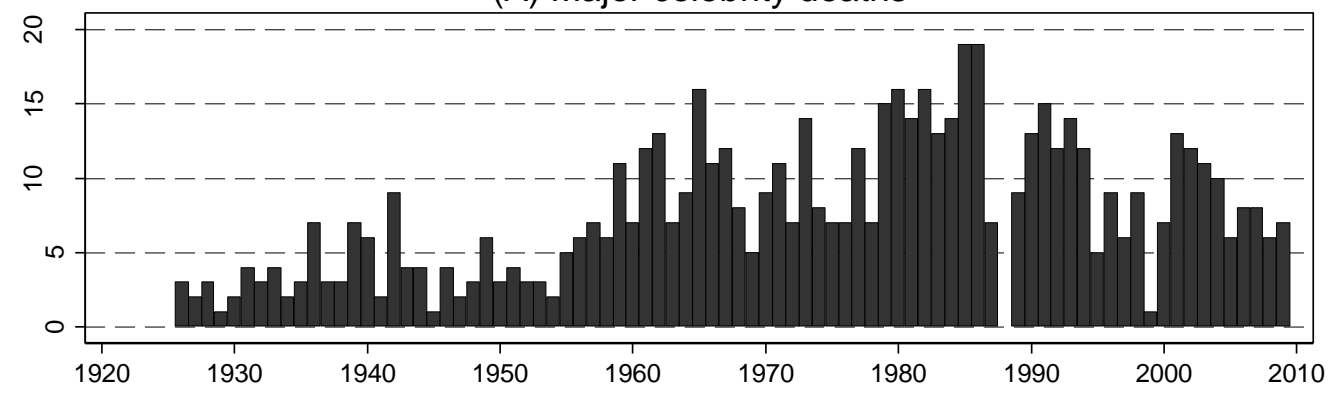

(B) Minor celebrity deaths

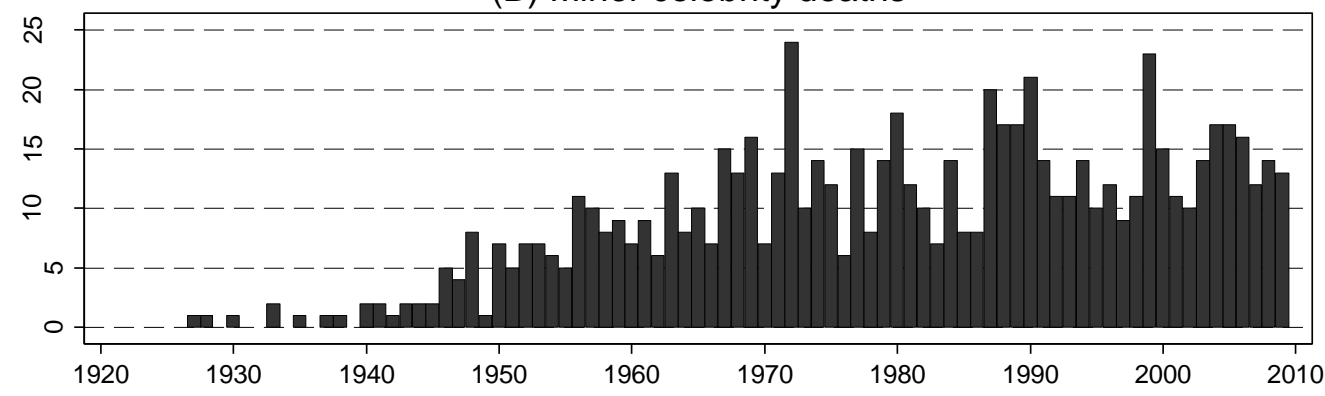

\section{Figure 1. Celebrity deaths by year}

This figure displays the death count of Hollywood Walk of Fame celebrities by year. Celebrities are sorted into major (Panel A) and minor (Panel B) depending on how often their names were mentioned in articles published in The New York Times, The Los Angeles Times, and The Chicago Tribune in the seven days following their death. More specifically, a celebrity is defined as a major (minor) celebrity if the number of such articles is greater than (less than or equal to) the unconditional sample median. The sample period ends in 2009 because the Google News Archive project, from which I collected the data to estimate the popularity of the celebrities in the sample, was discontinued by Google, Inc. at the beginning of the 2010s (Keller, 2011). 


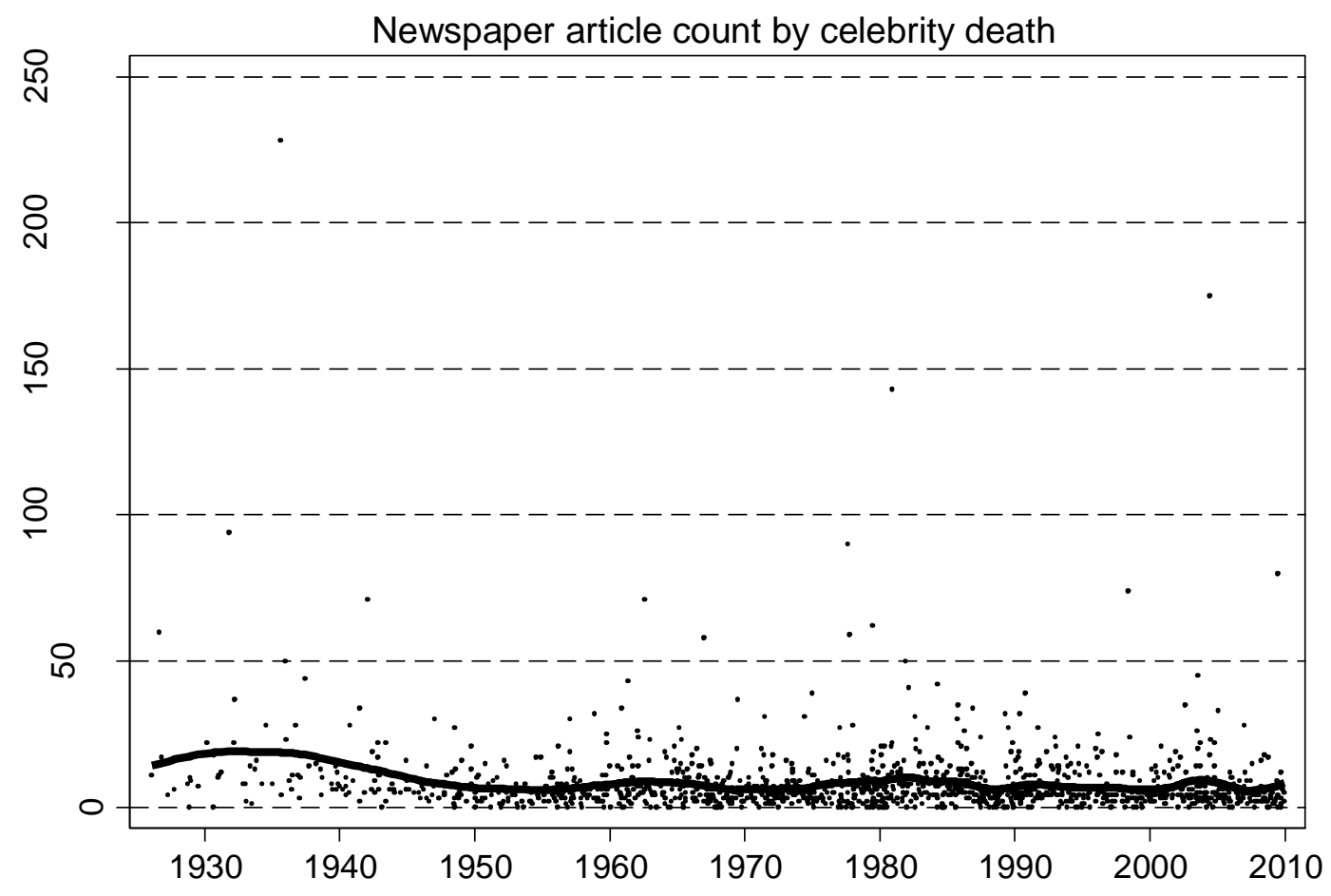

\section{Figure 2. Press coverage of celebrity deaths}

Each dot represents the combined number of articles published in The New York Times, The Los Angeles Times, and The Chicago Tribune that mentioned the name of a celebrity in the sample in the seven days following his or her death. The solid line is a locally weighted scatterplot smoother ("lowess") fitted using running-line least square smoothing with a bandwidth equal to $10 \%$ of the data. The smoothing line aims at capturing possible changes in journalistic tastes and in the amount of attention that the mass media devoted to celebrities. In unreported robustness tests, I sorted the celebrities in the sample into major and minor depending on whether the dots representing them lay above or below the smoother; the results were analogous to the ones obtained in the main analysis and described in section 6 . 


\section{Sentiment and stock returns}

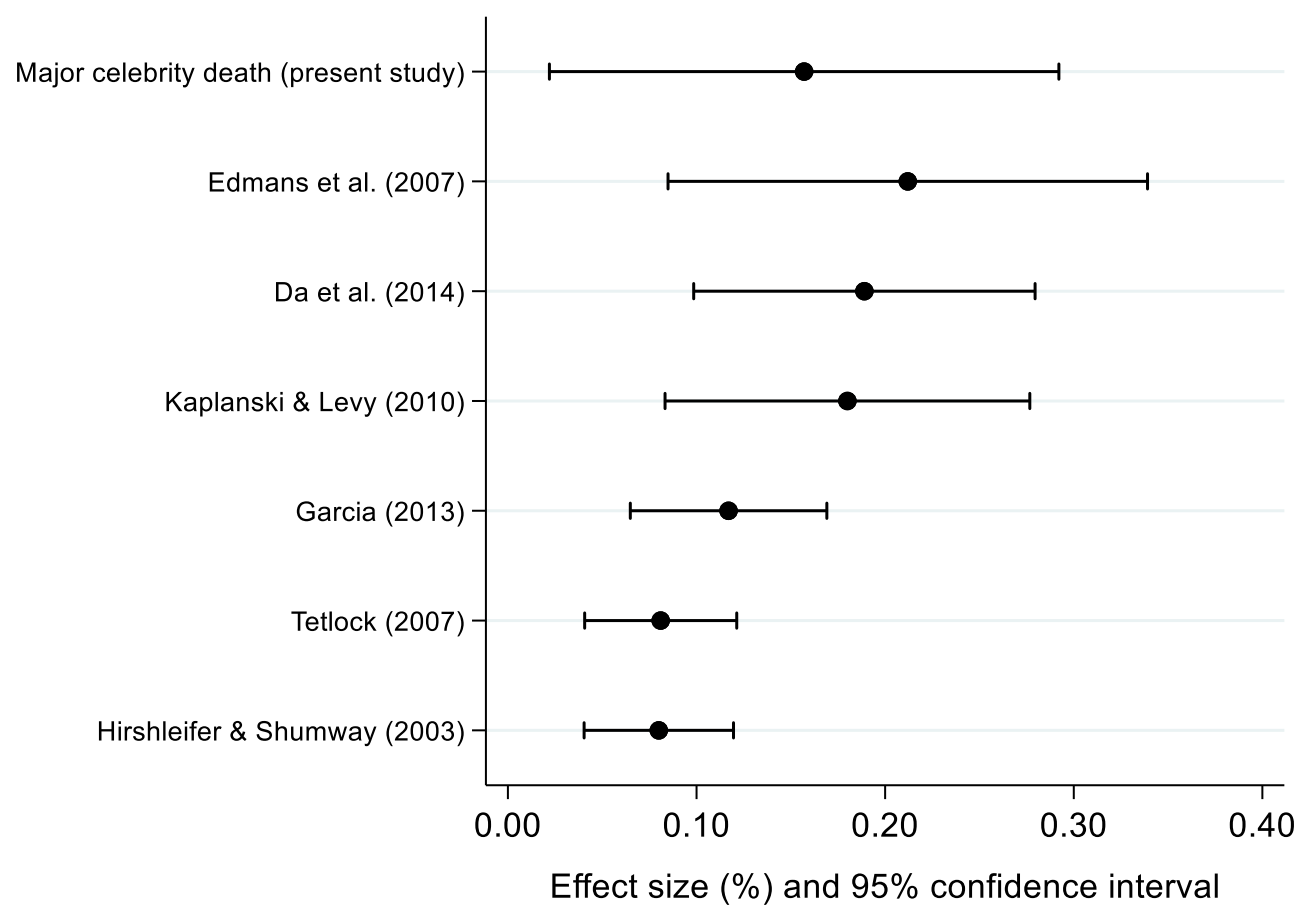

\section{Figure 3. Economic significance of the celebrity-death effect}

Point estimates and 95\% confidence intervals for the celebrity-death effect presented in this study and the sentiment effects reported in studies (using data at a daily frequency) published in The Journal of Finance, The Journal of Financial Economics, and the Review of Financial Studies. To facilitate comparisons, all effects are displayed in absolute value. In all cases, it is the baseline result that is shown in the figure (rather than the largest point estimate reported in the study, which often appears in the abstract or in the introduction of the article). Edmans et al. (2007) found that national teams' losses in international competitions are followed by a decrease in stock returns of $0.21 \% \pm 0.13 \%$ (Table II, Panel A, row 1, column 5). Da et al. (2014) found that a one-standard-deviation increase in their FEARS sentiment index is accompanied by a decrease in returns of $0.19 \% \pm 0.09 \%$ (Table 2, row 1, column 1). Kaplanski and Levy (2010) reported that aviation disasters are followed by a decrease in returns of $0.18 \%$ $\pm 0.10 \%$ (Table 2, row 1, column 13). Garcia (2013) documented that a one-standard-deviation increase in media pessimism during recessions is followed by a decrease in returns of $0.12 \% \pm 0.05 \%$ (Table IV, panel B, row 1, column 5). Tetlock (2007) found that a one-standard-deviation increase in media pessimism is followed by a decrease in returns of $0.08 \% \pm 0.04 \%$ (Table II, row 1, column 1). Hirshleifer and Shumway (2003) reported that a change in cloud cover from $8(\max )$ to $0(\min )$ is accompanied by an increase in stock returns of $0.08 \% \pm 0.04 \%$ (Table III, last row, column 2). The confidence interval for the celebrity-death effect is from Table A2 in the online Appendix, row 1 and 2, column 2. 


\section{Table 1. Summary statistics}

This table reports descriptive statistics for the main variables employed in the analysis. Stock returns are in percent per day (Panel A). In Panel B, trading volume refers to the daily number of shares traded at the NYSE (in millions). Panel C contains dummies used to control for seasonalities in stock returns: PreH and PostH take value 1 on the trading day that precedes and follows each major U.S. holiday, respectively, and 0 otherwise; TOM takes value 1 on the first three trading days and the last trading day of each month, and 0 otherwise; January takes value 1 if the trading day is in January, and 0 otherwise; SMGA takes value 1 on trading days between November 1 and April 30, and 0 otherwise; Week 43 takes value 1 between October 22 and October 28 of each year, and 0 otherwise, while Week44 takes value 1 between October 29 and November 4 of each year, and 0 otherwise; DST takes value 1 on the trading day that immediately follows a daylight saving time change in the U.S., and 0 otherwise. Panel D contains a set of behavioral factors: SADOR is the SAD onset/recovery proxy that Kamstra et al. (2015) employed to track changes in investor risk aversion across the seasons; NewMoon (FullMoon) takes value 1 from day $t$-3 through $t+3$, and 0 otherwise, where $t$ is a new (full) moon date; GMStorm takes value 1 on day $t$ and $t+1$ if the c9 geomagnetic index, available from January 1, 1932, is greater than or equal to 6 on day $t$, and 0 otherwise.

\begin{tabular}{lccccc}
\hline \hline & Observations & Mean & Std & Min & Max \\
\hline Panel A: Stock returns & & & & & \\
\hline CRSP equal-weighted log return (1/2/1926-12/31/2009) & 22,276 & 0.081 & 1.059 & -14.56 & 18.48 \\
CRSP value-weighted log return (1/2/1926-12/31/2009) & 22,276 & 0.034 & 1.064 & -18.80 & 14.41 \\
& & & & & \\
& & & & & \\
\hline Panel B: Trading volume & & & & & \\
\hline NYSE trading volume (millions of shares) & 22,276 & 251.637 & 573.164 & 0.030 & $6,106.8$ \\
& & & & & \\
\hline Panel C: Seasonal factors & & & & & \\
\hline Pre-holiday (PreH) & 22,276 & 0.031 & 0.173 & 0 & \\
Post-holiday (PostH) & 22,276 & 0.031 & 0.173 & 0 & 1 \\
Turn of the month (TOM) & 22,276 & 0.181 & 0.385 & 0 & 1 \\
January & 22,276 & 0.085 & 0.278 & 0 & 1 \\
Sell in May \& go away (SMGA) & 22,276 & 0.494 & 0.500 & 0 & 1 \\
Week 43 & 22,276 & 0.020 & 0.140 & 0 & 1 \\
Week 44 & 22,276 & 0.019 & 0.137 & 0 & 1 \\
Daylight saving time (DST) & 22,276 & 0.007 & 0.085 & 0 & 1 \\
& & & & & \\
\hline Panel D: Behavioral factors & & & & & \\
\hline Seasonal affective disorder (SADOR) & & & & & \\
NewMoon & 22,276 & -0.001 & 0.214 & -0.433 & 0.433 \\
FullMoon & 22,276 & 0.238 & 0.426 & 0 & 1 \\
Geomagnetic storm (GMStorm) & 22,276 & 0.235 & 0.424 & 0 & 1 \\
\hline \hline
\end{tabular}




\section{Table 2. Baseline model and seasonalities}

Columns (1) and (2) in this table report the results of fitting equation [1] by OLS, and columns (3) and (4) report the results of fitting equation [2] by OLS. MajorCeleb (MinorCeleb) is a dummy that takes value 1 on days $t$ and $t+1$, provided the market is open, if a major (minor) celebrity, as defined in section 5, dies on day $t$, and 0 otherwise. Equation [2] contains a set of dummy variables, e.g. PreH, to control for known seasonalities in stock returns. Returns are in percent per day. The pvalues in parentheses were computed using Newey-West heteroskedasticity and serial correlation robust standard errors (up to 5 lags). The p-values in the last row of the table refer to a test of the null hypothesis that the coefficient on MajorCeleb is equal to the coefficient on MinorCeleb. $* * *, * *, *$ indicate statistical significance at the $0.01,0.05$ and 0.10 level, respectively.
(1)
(2)
(3)
(4)

CRSP equal- CRSP value- CRSP equal- CRSP valueweighted returns weighted returns weighted returns weighted returns

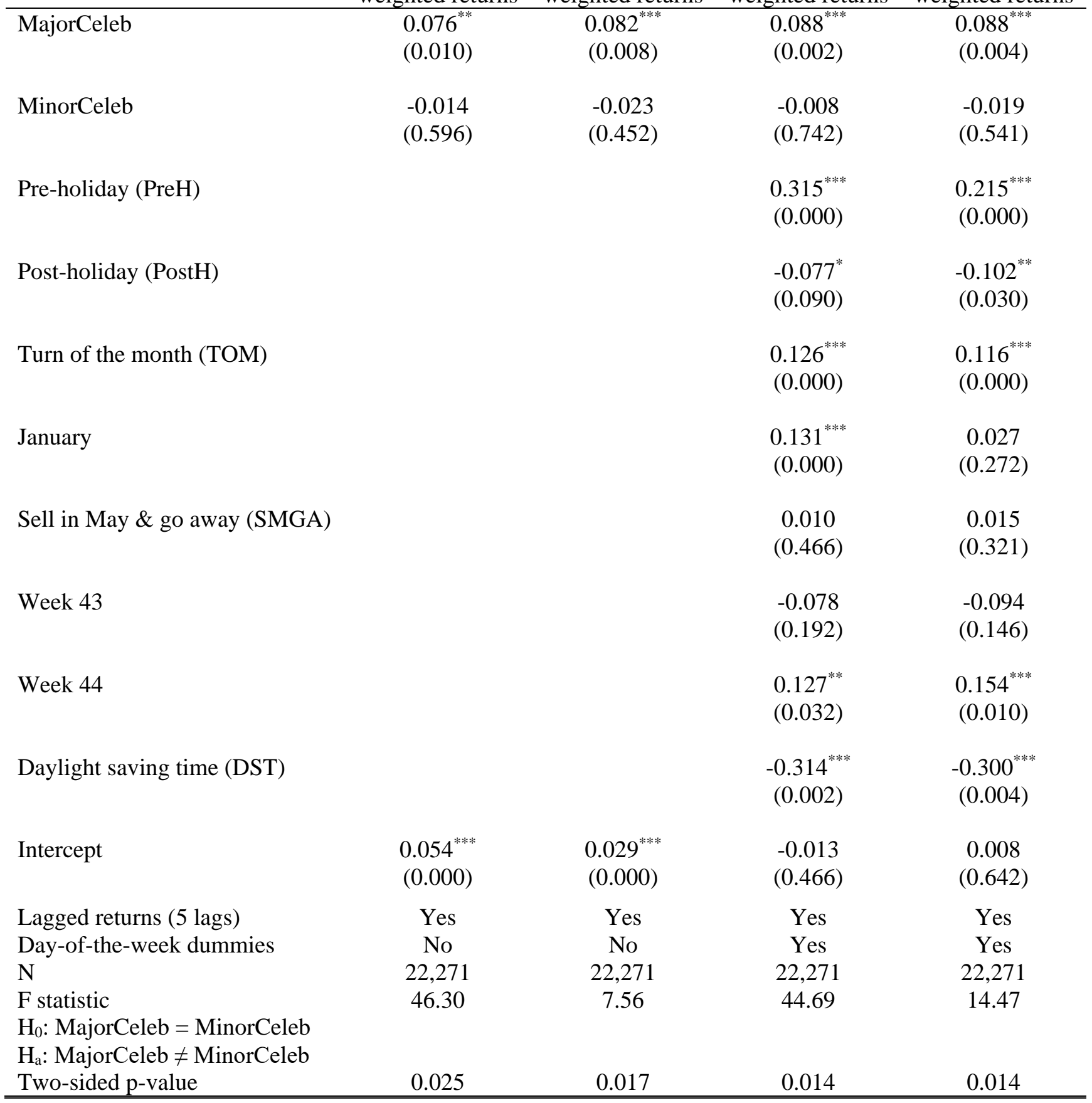




\section{Table 3. Liquidity, market frictions, and behavioral factors}

Columns (1) and (2) in this table report the results of fitting equation [3] by OLS, and columns (3) and (4) report the results of fitting equation [4] by OLS. Returns are in percent per day. MajorCeleb (MinorCeleb) is a dummy that takes value 1 on days $t$ and $t+1$, provided the market is open, if a major (minor) celebrity, as defined in section 5 , dies on day $t$, and 0 otherwise. Equations [3] and [4] contain 5 lags of detrended NYSE trading volume and 5 lags of detrended CRSP returns volatility to control for the influence of liquidity and other possible market frictions as in Tetlock (2007). Equation [4] also contains a set of covariates to control for the influence of known behavioral factors. The p-values in parentheses were computed using Newey-West heteroskedasticity and serial correlation robust standard errors (up to 5 lags). The p-values in the last row of the table refer to a test of the null hypothesis that the coefficient on MajorCeleb is equal to the coefficient on MinorCeleb. $* * *, * *, *$ indicate statistical significance at the $0.01,0.05$ and 0.10 level, respectively.

\begin{tabular}{|c|c|c|c|c|}
\hline & $\begin{array}{c}\text { (1) } \\
\text { CRSP equal- } \\
\text { weighted returns }\end{array}$ & $\begin{array}{c}\text { (2) } \\
\text { CRSP value- } \\
\text { weighted returns }\end{array}$ & $\begin{array}{c}\text { (3) } \\
\text { CRSP equal- } \\
\text { weighted returns }\end{array}$ & $\begin{array}{c}\text { (4) } \\
\text { CRSP value- } \\
\text { weighted returns }\end{array}$ \\
\hline MajorCeleb & $\begin{array}{c}0.088^{* * *} \\
(0.003)\end{array}$ & $\begin{array}{l}0.089^{* * * *} \\
(0.004)\end{array}$ & $\begin{array}{l}0.085^{* * *} \\
(0.004)\end{array}$ & $\begin{array}{l}0.083^{* * *} \\
(0.007)\end{array}$ \\
\hline MinorCeleb & $\begin{array}{c}-0.009 \\
(0.720)\end{array}$ & $\begin{array}{l}-0.015 \\
(0.613)\end{array}$ & $\begin{array}{l}-0.016 \\
(0.545)\end{array}$ & $\begin{array}{c}-0.022 \\
(0.471)\end{array}$ \\
\hline Pre-holiday (PreH) & $\begin{array}{c}0.323^{* * *} \\
(0.000)\end{array}$ & $\begin{array}{c}0.221^{* * * *} \\
(0.000)\end{array}$ & $\begin{array}{c}0.293^{* * *} \\
(0.000)\end{array}$ & $\begin{array}{c}0.203^{* * *} \\
(0.000)\end{array}$ \\
\hline Post-holiday (PostH) & $\begin{array}{l}-0.056 \\
(0.214)\end{array}$ & $\begin{array}{l}-0.089^{*} \\
(0.060)\end{array}$ & $\begin{array}{c}-0.051 \\
(0.285)\end{array}$ & $\begin{array}{l}-0.084^{*} \\
(0.084)\end{array}$ \\
\hline Turn of the month (TOM) & $\begin{array}{l}0.131^{* * * *} \\
(0.000)\end{array}$ & $\begin{array}{l}0.119^{* * * *} \\
(0.000)\end{array}$ & $\begin{array}{l}0.126^{* * * *} \\
(0.000)\end{array}$ & $\begin{array}{l}0.115^{* * * *} \\
(0.000)\end{array}$ \\
\hline January & $\begin{array}{c}0.123^{* * * *} \\
(0.000)\end{array}$ & $\begin{array}{c}0.022 \\
(0.361)\end{array}$ & $\begin{array}{c}0.125^{* * *} \\
(0.000)\end{array}$ & $\begin{array}{c}0.018 \\
(0.466)\end{array}$ \\
\hline Sell in May \& go away (SMGA) & $\begin{array}{c}0.013 \\
(0.359)\end{array}$ & $\begin{array}{c}0.016 \\
(0.282)\end{array}$ & $\begin{array}{c}-0.012 \\
(0.492)\end{array}$ & $\begin{array}{c}0.000 \\
(0.991)\end{array}$ \\
\hline Week 43 & $\begin{array}{l}-0.087 \\
(0.153)\end{array}$ & $\begin{array}{c}-0.079 \\
(0.200)\end{array}$ & $\begin{array}{c}-0.074 \\
(0.203)\end{array}$ & $\begin{array}{l}-0.055 \\
(0.310)\end{array}$ \\
\hline Week 44 & $\begin{array}{l}0.114^{* *} \\
(0.039)\end{array}$ & $\begin{array}{l}0.139^{* *} \\
(0.021)\end{array}$ & $\begin{array}{l}0.119^{* *} \\
(0.029)\end{array}$ & $\begin{array}{c}0.153^{* * *} \\
(0.009)\end{array}$ \\
\hline Daylight saving time (DST) & $\begin{array}{c}-0.319^{* * *} \\
(0.001)\end{array}$ & $\begin{array}{c}-0.272^{* * *} \\
(0.003)\end{array}$ & $\begin{array}{c}-0.286^{* * *} \\
(0.007)\end{array}$ & $\begin{array}{c}-0.252^{* *} \\
(0.010)\end{array}$ \\
\hline Seasonal affective disorder (SADOR) & & & $\begin{array}{l}-0.079^{*} \\
(0.076)\end{array}$ & $\begin{array}{c}-0.052 \\
(0.262)\end{array}$ \\
\hline NewMoon & & & $\begin{array}{c}0.017 \\
(0.311)\end{array}$ & $\begin{array}{c}0.022 \\
(0.222)\end{array}$ \\
\hline FullMoon & & & $\begin{array}{c}0.006 \\
(0.695)\end{array}$ & $\begin{array}{c}0.010 \\
(0.573)\end{array}$ \\
\hline Geomagnetic storm (GMStorm) & & & $\begin{array}{l}-0.028^{*} \\
(0.067)\end{array}$ & $\begin{array}{l}-0.026 \\
(0.107)\end{array}$ \\
\hline Intercept & $\begin{array}{l}-0.008 \\
(0.674)\end{array}$ & $\begin{array}{c}0.008 \\
(0.666)\end{array}$ & $\begin{array}{c}0.009 \\
(0.696)\end{array}$ & $\begin{array}{c}0.017 \\
(0.424)\end{array}$ \\
\hline Lagged returns (5 lags) & Yes & Yes & Yes & Yes \\
\hline Day-of-the-week dummies & Yes & Yes & Yes & Yes \\
\hline Detrended trading volume (5 lags) & Yes & Yes & Yes & Yes \\
\hline Detrended returns volatility (5 lags) & Yes & Yes & Yes & Yes \\
\hline $\mathrm{N}$ & 22,229 & 22,229 & 20,492 & 20,492 \\
\hline $\begin{array}{l}\text { F statistic } \\
\mathrm{H}_{0}: \text { MajorCeleb }=\text { MinorCeleb } \\
\mathrm{H}_{\mathrm{a}}: \text { MajorCeleb } \neq \text { MinorCeleb }\end{array}$ & 34.85 & 11.16 & 28.27 & 9.02 \\
\hline Two-sided p-value & 0.012 & 0.015 & 0.011 & 0.014 \\
\hline
\end{tabular}




\section{Table 4. A trading strategy based on celebrity deaths}

This table reports the results of a trading strategy that involves alternating between a long position in the risk-free asset (the status quo) and a long position in S\&P 500 futures (when a major celebrity dies). Fractional purchases of futures contracts are not allowed; instead, it is assumed that any amount left after the purchase of S\&P 500 futures remains invested in the riskfree asset. The sample covers the period from April 23, 1982, when the CME introduced the S\&P 500 futures contract, through December 31, 2009, and the starting capital is \$1 million. When estimating the trading strategy's CAPM alpha, the S\&P 500 index proxies for the market portfolio and the risk-free rate of return is from Kenneth French's website. Panels A and B assume that the investor has perfect foresight of celebrity deaths, whereas no such assumption is made in Panels $\mathrm{C}$ and $\mathrm{D}$. The average number of roundtrip trades (purchase and sale of S\&P 500 futures) is 7.5 per year with perfect foresight and 6.6 per year without perfect foresight. In Panels A and C, it is assumed that the trading strategy entails no transaction costs, whereas in Panels B and D the following assumptions are made about transaction costs: the bid-ask spread of the S\&P 500 futures contract is 0.05 index points between April 1982 and December 1987 (Stoll and Whaley, 1990), 0.06 index points between January 1988 and October 1997 (Bollen et al., 2003), and 0.37 index points between November 1997 and December 2009 (Smimou, 2017), and the commission fees are \$25 per contract per trade (including exchange fees and floor brokerage) for institutional investors (Huang and Stoll, 1998). Each panel displays the results of the trading strategy for three hypothesized margin levels: $100 \%, 50 \%$, and $20 \%$. Since, throughout the trading simulation, the value of the margin deposit is always greater than or equal to $16 \%$ of the value of the futures position, it is assumed that no margin calls are triggered. To add a layer of conservatism to the analysis, it is assumed that the investor does not earn any interest on the futures margin deposit.

\section{Perfect foresight}

When a major celebrity dies on day $t$, the portfolio is invested in S\&P 500 futures at the end of day $t-1$, and the futures position is liquidated at the end of day $t+1$; at all other times, the portfolio is long in the risk-free asset.

Panel A: No transaction costs

\begin{tabular}{cccc}
\hline Margin & $\begin{array}{c}\text { Geometric mean raw } \\
\text { return }(\% / \text { year })\end{array}$ & CAPM Alpha (\%/year) & Beta \\
\hline $100 \%$ & 6.80 & 1.68 & 0.04 \\
$50 \%$ & 8.88 & 3.48 & 0.07 \\
$20 \%$ & 14.38 & 8.05 & 0.18
\end{tabular}

Panel B: Transaction costs included

\begin{tabular}{cccc}
\hline Margin & $\begin{array}{c}\text { Geometric mean raw } \\
\text { return (\%/year) }\end{array}$ & CAPM Alpha (\%/year) & Beta \\
\hline $100 \%$ & 6.48 & 1.38 & 0.04 \\
$50 \%$ & 8.23 & 2.88 & 0.07 \\
$20 \%$ & 12.66 & 6.54 & 0.18 \\
\hline
\end{tabular}

No perfect foresight

When a major celebrity dies on day $t$, the portfolio is invested in S\&P 500 futures at the end of day $t$, and the futures position is liquidated at the end of day $\mathrm{t}+1$; at all other times, the portfolio is long in the risk-free asset.

Panel C: No transaction costs

\begin{tabular}{cccc}
\hline Margin & $\begin{array}{c}\text { Geometric mean raw } \\
\text { return (\%/year) }\end{array}$ & CAPM Alpha (\%/year) & Beta \\
\hline $100 \%$ & 5.76 & 0.76 & 0.02 \\
$50 \%$ & 6.75 & 1.64 & 0.03 \\
$20 \%$ & 9.28 & 3.81 & 0.08
\end{tabular}

Panel D: Transaction costs included

\begin{tabular}{cccc}
\hline Margin & $\begin{array}{c}\text { Geometric mean raw } \\
\text { return (\%/year) }\end{array}$ & CAPM Alpha (\%/year) & Beta \\
\hline $100 \%$ & 5.61 & 0.62 & 0.02 \\
$50 \%$ & 6.39 & 1.30 & 0.03 \\
$20 \%$ & 8.36 & 2.97 & 0.08 \\
\hline \hline
\end{tabular}

